\title{
Estudo de caso sobre os desafios do jornalismo institucional na perspectiva da comunicação pública
}

\section{Case study on the challenges of institutional journalism from the perspective of public communication}

\author{
Antonio Carlos Sardinha

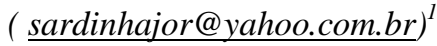 \\ Cecília Soares de Paiva \\ (cecilpaiva@hotmail.com $)^{2}$ \\ http://dx.doi.org/10.5216/cei.v14i1.21502
}

\begin{abstract}
Resumo
O artigo apresenta breve reflexão sobre o campo da Comunicação Pública e os desafios do jornalismo em instituições públicas. A partir de estudo de caso, busca-se compreender a dinâmica dos fluxos de informação e da atuação jornalística no Ministério Público do Estado de Mato Grosso do Sul e indicar os desafios conceituais para operar uma política de comunicação na perspectiva da Comunicação Pública no âmbito dessa instituição do sistema de justiça brasileiro. Destaca-se a atuação da assessoria de comunicação sob viés organizacional e publicista, resistente à perspectiva pública da comunicação como meio para a promoção da cidadania e do direito à informação. O estudo revela um dos inúmeros desafios das instituições públicas no que se refere às suas políticas e ações de comunicação, em tempos de demanda por transparência, participação e acesso à informação de interesse coletivo.
\end{abstract}

Palavras-chave: Comunicação Pública. Jornalismo Institucional. Políticas de Comunicação. Cidadania.

\begin{abstract}
The article presents a brief reflection on the field of public communication and the challenges of journalism in public institutions. From the case study, we seek to understand the dynamics of information flows and performance in journalistic prosecutor of Mato Grosso do Sul and indicate the conceptual challenges to operate a communication policy from the perspective of public communication under this institution of the Brazilian justice system. We highlight the performance of communications consultancy in organizational bias and publicist, resistant to the prospect of public communication as a means to promote citizenship and the right to information. The study reveals one of many challenges of public institutions with regard to its policies and actions of communication in times of demand for transparency, participation and access to information of public interest.
\end{abstract}

Keywords: Public Communication. Institutional Journalism. Communication Policy. Citizenship.

\footnotetext{
${ }^{1}$ Jornalista, mestre em Comunicação (UNESP). Pesquisador do Grupo de Pesquisa Comunicação, Cultura e Sociedade (Universidade Estadual do Estado de Mato Grosso-UNEMAT).

${ }^{2}$ Relações públicas e jornalista, mestre em Comunicação (UNESP).
} 


\section{Introdução}

O papel do jornalismo nas instituições públicas está entre os tópicos que envolvem o debate sobre a atividade jornalística contemporânea.

Pela premissa de que há diferentes modos de exercer o jornalismo, na perspectiva de que a produção de notícias relaciona-se com a provocação de agendamentos em busca de visibilidade desejada por atores e instituições (WEBER; COELHO, 2011, p.52), há de se problematizar os limites, desafios e perspectivas que envolvem o jornalismo no espaço das instituições públicas, permeadas por interesses e disputas relativas à formulação e/ou implementação das políticas públicas por essas instituições (BONETI, 2006).

Registra-se ainda a necessidade de contribuir com o debate em curso sobre o papel das políticas de Comunicação para a democratização dos processos participativos e decisórios, de modo a ampliar a cidadania em tempos de midiatização das relações e da centralidade dos dispositivos midiáticos na tessitura das práticas sociais (VIZER, 2008; 2006 FAUSTO NETO, 2008).

A discussão é feita a partir de estudo de caso relativo ao fluxo da informação concernente à atuação do Ministério Público do Estado de Mato Grosso do Sul, tendo como espaço de observação e de coleta de dados a assessoria de comunicação e as produções jornalísticas do órgão. Os dados coletados impulsionam ao debate acerca dos desafios teórico-práticos que envolvem a comunicação na perspectiva do interesse público, peculiar à referida instituição.

Propõe-se a problematizar o jornalismo institucional no contexto das reflexões em curso, envolvendo o campo da Comunicação Pública. Assim, o artigo destaca, por meio de estudo empírico, aspectos conceituais que permeiam as práticas de comunicação em tempos de democratização, transparência e participação. Implicam-se, nesse cenário, as discussões sobre as políticas públicas brasileiras, e como o campo da comunicação, vislumbrado como serviço público, acompanha todas essas demandas.

\section{Comunicação Pública, Jornalismo Institucional e Democracia}

A partir do entendimento de Monteiro (2009), baseada em Wolton (2006), infere-se que o lócus da Comunicação Pública é o espaço simbolicamente organizado em um padrão/modelo de comunicação entre o Estado e a Sociedade, constituído por um espaço político (decisão), outros espaço públicos (discussão) e um espaço social (circulação) (MONTEIRO, 2009). 
É do fluxo de informação e comunicação que permeiam essas três esferas teoricamente ocupadas pela Comunicação Pública que, como política pública sistematizada e organizada, tende a utilizar-se de estratégias, dispositivos e práticas capazes de organizar simbolicamente uma esfera pública dinâmica, plural e com potencial de incidência em processos decisórios característicos das democracias.

Nessa linha, as ações de comunicação formuladas sobre essa perspectiva da Comunicação Pública favorece os processos democráticos quando não só produz e garante o acesso à informação de interesse público como organiza a circulação da informação (BRANDÃO, 2009) que permeia a instituição pública, tudo de maneira democrática e dialógica. No que tange ao jornalismo institucional sob essa perspectiva, a questão é fazer com que a produção de informação e de newsmaking (WOLF, 1995; SOUSA, 2002) das instituições incorpore as possibilidades de dispositivos e práticas geridas sob a perspectiva da Comunicação Pública (DUARTE, 2009).

É nesse sentido que se considera importante o mapeamento e a compreensão da dinâmica e natureza dos fluxos e o modelo de comunicação em uma organização como o Ministério Público, de forma a compreender como atua o jornalismo institucional e como estão organizadas as práticas e políticas de comunicação dessa instituição.

Para a finalidade dessa reflexão, baseamos-nos na tentava de conceituar a Comunicação Pública, empreendida por Matos (2009b). Para além da comunicação governamental, da comunicação eleitoral e do marketing político, a comunicação pública se articula com a comunicação política em uma esfera pública como local de interação social de todos os agentes e interesses envolvidos. Nessa esfera transitam recursos humanos (cidadãos, políticos e eleitores), físicos (suporte de comunicação massiva, tecnologias interativas e convergentes), econômicos (capital, ativos em geral), comunicacionais (discursos, debates, diálogos estruturados dentro e fora da mídia massiva e recursos interativos) (MATOS, 2009b, p.123).

A Comunicação Pública como esse ethos que referencia práticas, instrumentos e dispositivos pensados para organizar fluxos informação e espaços de comunicação entre Estado e Sociedade para questões de interesse público (DUARTE 2009) estabelece relação constitutiva com a democracia por interferir na distribuição de poder político. Isso por ser configurada, conforme Brandão (2009), como um processo de comunicação que se estabelece em uma esfera pública entre o Estado, Governo e Sociedade para ser um espaço privilegiado de negociação e de disputas nas sociedades políticas. 
Nesse sentido, portanto, a Comunicação Pública precisa ser pensada em um diálogo afinado com as teorias democráticas pela relação das políticas de comunicação com a prática da democracia, ao instituir o que Pitta (2001) denomina como um continuum, um dado padrão de conflitualidade na esfera pública e assim um dado modelo de democracia (PITTA, 2001).

A abertura de espaços democráticos como referência para pensar as políticas sociais brasileiras, a partir da década 1980, teoricamente reforça uma necessidade de revisar os modelos de comunicação entre Estado e Sociedade, em uma perspectiva de fortalecer a Comunicação Pública como elemento central para o debate sobre democratização dos processos de participação em torno das políticas públicas.

Esse reposicionamento exige, a priori, pensar na comunicação como uma política de Estado com diretrizes claras e como serviço permanente no conjunto dos serviços públicos, realidade ainda inexistente no país (SIGNATES, 2009, 2011; LASSANCE, 2010). Ao se pensar a Comunicação Pública como modelo teórico-instrumental de mediação das relações entre Estado e Sociedade, seguindo indicação de Matos (2009), e considerando a pontuação de que o padrão de conflitualidade está de acordo com a natureza dessas políticas de comunicação (PITTA, 2001), registra-se que:

a) Em uma leitura comunicacional com base na singularidade da Comunicação Pública (MONTEIRO, 2009), enquanto processo de comunicação com dispositivos e práticas específicas, nota-se que a gramática de participação (SANTOS, 2002) que permeou o arranjo democrático e a natureza das políticas públicas a partir da redemocratização, não acompanhou o desenho das políticas públicas na área de comunicação em geral e da Comunicação Pública em particular.

b) Essa constatação toma como pressupostos a ausência de regulamentação de políticas de comunicação (RAMOS e SANTOS, 2007); as restrições ao direito humano à comunicação (RAMOS, 2005); as questões de natureza teórica envolvendo conceito e dimensão da Comunicação Pública (BRANDÃO; DUARTE; MONTEIRO, 2009) e o delineamento histórico das políticas de Comunicação no interior do Estado (PITTA, 2001).

Seguindo no detalhamento para cada um dos aspectos acima, há de se destacar, como questão central, um vácuo na elaboração por parte do Estado de políticas de comunicação e o debate sobre direito humano à comunicação. O Estado, no papel de legalmente normatizar as demandas da área de comunicação, limitou-se a organizar e a gerir burocraticamente essas demandas, 
descomprometido com uma política mais ampla de regulamentação e implementação de políticas públicas para democratizar o espaço público monopolizado dos meios de comunicação no Brasil.

Para Souza (2007), as políticas democráticas de comunicação são entendidas como conjunto de ações coordenadas, decididas sob ampla participação para atender a demandas sociais. Sob essa ótica, o cenário brasileiro pode ser caracterizado por uma certa desregulamentação do setor, no sentido de sua abertura às diretrizes do mercado, afastado das possibilidades de construção de sistemas de comunicação públicos.

Tal cenário acompanha uma tendência que coloca a comunicação no conjunto da liberalização de trocas, flexibilidade de movimentação de recursos financeiros e da fluidez de redes planetárias como elementos da modernização, permeando uma ordem internacional para a informação e Comunicação que é hegemônica (MATTELART, 2006 ).

Especificamente sobre as políticas de comunicação no Brasil, Souza (2007) aponta que, pelas especificidades da formação política e econômica brasileira, a relação Estado-Mercado não foi marcada pela lógica impessoal das modernas relações de mercado, mas pela contradição entre as gramáticas políticas brasileiras vigentes e o imperativo de modernização da economia (SOUZA, 2007, p. 155).

Nesse sentido, podemos resumir que as políticas de comunicação no Brasil são marcadas pela hegemonia dos interesses do mercado nos moldes das relações estabelecidas no âmbito político brasileiro, definido na gramática apontada por Souza (2007), que incluem o clientelismo, o corporativismo (o peso do Estado como intermediador e conciliador de interesses diversos), o insulamento burocrático (estratégia das elites para driblar as decisões políticas) e o universalismo de procedimentos (associado à competência técnica da burocracia que legitimam as decisões).

A concentração das propriedades de mídia, a ausência de critérios claros e procedimentos públicos para concessão e autorização para funcionamento de meios de comunicação, a ausência de espaços decisórios coletivos para discutir as diretrizes das políticas para a área caracterizam o estado das políticas públicas de comunicação no país ao longo da história.

No caso específico da Comunicação Pública delineada sob a perspectiva das instituições públicas estatais, a situação é ainda mais complexa. Para Signates (2009), no Brasil, o problema perpassa âmbitos teórico-práticos que incluem formulações teóricas sobre comunicação estatal (encontradas normalmente no campo das relações públicas), até a aplicação de política e 
estruturação normativa e burocrática das funções de secretarias de comunicação nas diferentes esferas de governo (SIGNATES, 2009, p.11).

Essa compreensão se reflete na tentativa de potencializar recursos do Estado para dominar a fala como relação central do modelo de comunicação entre Estado e Sociedade por meio da mídia. Isso reflete em um condicionamento da comunicação com a sociedade a uma publicidade de governo e centralização exclusiva desse espaço para travar as lutas políticas.

A questão a se pontuar é se não há um descompasso das ações comunicativas que sustentaram o pacto modernizador ao longo dos anos no país: em linhas gerais, se ainda é pertinente a ideia da comunicação como instância para auxiliar o projeto de integração social de governos, para a gestão de imagem e para formatar/enformar conflitos. Situações essas distanciadas das demandas da própria democracia contemporânea.

Com a redemocratização, a entrada de novos atores, as demandas por cidadania e a criação de novos espaços na cena democrática brasileira, há ampliação, embora não necessariamente democratizem, dos espaços de diálogo, negociação e disputas. Assim, o modelo e as políticas de comunicação elaboradas no âmbito do Estado como estratégia de relacionamento com a sociedade forçam a um reposicionamento sobre o sentido que a Comunicação assume no conjunto do aparato estatal.

Nesse sentido, a crítica de Lassance (2010) faz sentido ao destacar que a ideia de que se tentou propagar como "modelo" de comunicação para o setor público não tem lastro teórico algum. A comunicação pública está baseada no local onde ela é praticada, nesse caso, nos espaços públicos. Para o autor a discussão até ganharia algum sentido "se partisse da teoria da participação, que encontra alguma afinidade com a concepção habermasiana de esfera pública, ou estivesse associada à teoria da democracia deliberativa. Mas não foi assim que a idéia foi recepcionada no Brasil”. (LASSANCE, 2010, p.169).

Sob a ausência de regulamentação de políticas públicas em comunicação do poder público, pesa, além da ausência do "lastro teórico", uma perspectiva epistêmica mais robusta. Compartilhase da perspectiva de Signates (2011) que entende a necessidade de considerar a contribuição da comunicação ao pensamento social, ao emergir como categoria analítica para interpretar os processos sociais.

Essa compreensão requer, antes de pensar a comunicação como política pública, entender a sua relação constitutiva com a democracia, ou seja, como o modo de ser e como garantidora do 
regime democrático (SIGNATES, 2011, p.6-7). No primeiro caso, a comunicação representa o modo de ser da democracia pela possibilidade de produção e circulação de sentidos - aspecto fundamental para caracterizar uma sociedade democrática; no segundo caso, pela possibilidade de uma esfera pública ampliada e livre para a manifestação do pensamento e circulação de ideias e informações, gradientes de democraticidade nas palavras do próprio autor (SIGNATES, 2011).

Em uma avaliação da configuração contemporânea da comunicação pública do Estado por meio dos seus respectivos dispositivos, produtos e processos de comunicação, Weber e Coelho (2011) pontuam a hipótese de que são fornecidos elementos para exercício da cidadania pela disponibilização de mais informação. Isso no entanto, amplia e qualifica a propaganda sob outros modos e formatos. Chega-se, conforme as autoras, a um paradoxo:

ampliação dos processos de transparência, exposição e, consequentemente, aumento da vulnerabilidade; de outro, ampliação da capacidade de informar e persuadir. Mais acessibilidade a informações e, ao mesmo tempo, maior domínio de resultados e das relações. Identifica-se uma burocracia organizada para sustentar a comunicação dos poderes. Para tanto, reúne tecnologia e profissionais que transformam vultosos investimentos em matéria informativa, eventos, serviços, propaganda e notícias capazes de traduzir e justificar o projeto político e institucional do Executivo, Legislativo e Judiciário. (WEBER e COELHO, 2011, p.66)

A compreensão da centralidade da comunicaçãos no trato das questões políticas e de sua relação constitutiva com a democracia, conforme apontado, fortalecem do ponto de vista conceitual, epistêmico e político a responsabilidade estatal na formulação e implementação de políticas públicas para a comunicação nas democracias.

E se essas políticas correspondem a um modelo/imagem de Estado conforme apontamos em Pitta (2001) e Signates (2011), com destaque para a configuração que este último faz do Estado como lugar e produção da cidadania, ou Estado Cidadão, comunicativo (que entendemos ser o processo pelo qual passa o Estado Brasileiro desde a redemocratização com a aprovação da Constituição de 1988), pontua-se que:

- as políticas para a Comunicação Pública tem relação direta com o fortalecimeno de uma esfera pública robusta, plural e amplificada, que no arranjo democrático brasileiro (AVRITZER, 
2002) tem um relação estruturante com a deliberação e os processos decisórios envolvendo as políticas públicas (SARDINHA, 2011).

Para Signates (2011), trata-se de criar uma situação social, política, cultural e administrativa que favoreça a inversão da lógica do poder e do controle, na relação entre Estado (instituição por excelência de poder) e sociedade (p.17).

O desafio, no caso específico do jornalismo institucional, é lidar com uma contradição aparente, mas não muito evidente. A dimensão pública do jornalismo institucional está colada a uma dimensão estratégica pela necessidade de obter visibilidade, o que elimina o espaço para o contraditório e para críticas ao jornalismo produzido (WEBER e COELHO, 2011).

A questão é saber, no entanto, como garantir ao máximo o direito à informação e à comunicação por meio de uma perspectiva pública do jornalismo institucional, estando este diante da demanda por visibilidade e de uma imagem pública que caminha tendente ao publicismo das ações estatais, com nítidas estratégias de controle do processo de comunicação e da informação, mesmo diante (e a partir) da ampliação dos dispositivos comunicacionais de escuta, participação e diálogo.

\section{Procedimentos metodológicos e caracterização do estudo}

Concernente a essas reflexões, este artigo traz a ideia central e os resultados de pesquisa feita entre 2010/2011, relacionado ao Ministério Público do Estado de Mato Grosso do Sul (MPMS). Para contextualizar, é preciso dizer que, após a promulgação da Constituição Brasileira de 1988 (CF-1988), diversas organizações públicas receberam determinações específicas para garantir a condição democrática do país, a exemplo do que é disposto constitucionalmente para o Ministério Público (MP).

Ao declarar o MP como defensor de direitos constitucionais, a Constituição delega aos cargos de execução do órgão, promotores e procuradores de justiça, o poder de agir em favor do interesse público, visando normatizar as relações sociais e individuais dos sujeitos em comunidade. Além da atuação perante os crimes contra a vida, o Ministério Público também atua em favor dos direitos difusos e coletivos como o meio ambiente, patrimônio público, saúde, educação, pessoas e grupos em situação de vulnerabilidade como crianças, jovens e idosos, entre outros temas da democracia brasileira. 
O Ministério Público é formado pelo Ministério Público da União e Ministérios Públicos dos Estados, em que destacamos o MPMS como espaço para este estudo de caso. Por sua atuação em questões de interesse público, partiu-se da necessidade de compreender as ações e as políticas de comunicação do órgão no atendimento ao direito à informação, especificamente por meio do estudo do fluxo das informações no espaço institucional do MPMS.

Considera-se, na análise conceitual, que em tese, o jornalismo institucional sob a perspectiva da Comunicação Pública vincula-se à proposta de dar visibilidade a interesses prioritários de uma comunidade, no "desdobramento plural da vida, em seus aspectos de uma totalidade que envolve a política, a economia, a cultura, a história humana e sua multiplicidade de linguagem, significados e relações internas na constituição do cotidiano (KARAM, 1997, p.114). Definiu-se, então, investigar os procedimentos de assessoria de comunicação, sobretudo a partir das atribuições do campo do jornalismo nesse contexto de comunicação integrada, que estavam relacionadas à gestão dos fluxos de informação de interesse público, revelando as condições exigidas pelo método do estudo de caso, no seu caráter exploratório-descritivo da pesquisa em suas fases documentais e de investigações a campo (YIN, 2005; DUARTE, 2005).

Para a consistência de um corpus analítico de pesquisa, reuniu-se um conjunto de enunciados representado por avaliações bibliográficas e documentais, observações no cotidiano da assessoria de comunicação da instituição, produções comunicacionais e informacionais, levantamento das estratégias de gestão comunicacional, entrevistas e questionários dirigidos a pessoas-chaves que o estudo de caso pode contemplar (YIN, 2005, p.97).

Este artigo apresenta, tão somente, parte dos dados coletados para o estudo de caso ${ }^{3}$. Especificamente reflete como estratégia analítica (YIN 2055, 149-170), o caminho da informação institucional e a sua apropriação pelas ações de comunicação do MPMS. A partir do procedimento comum de a organização publicizar os seus atos por meio de informativo oficial (Diário Oficial do Ministério Público do Estado de Mato Grosso/DOMP) - publicado no site institucional do órgão - é feita a análise dessas publicações e, por elas, qual foi o aproveitamento/tratamento dado pela assessoria de comunicação do órgão (conhecida por Assecom).

\footnotetext{
${ }^{3}$ Estudo de caso consistente na dissertação de mestrado intitulada "A Comunicação da Informação de Interesse Público no Ministério Público do Estado de Mato Grosso do Sul”, especificações em Paiva (2011).
} 
A delimitação dos editais como informação de interesse no estudo se fez por estes reunirem condições suficientes para esclarecê-lo a atuação ministerial e a demanda por notícias. Publicados, oficializam o comprometimento da instituição com a sociedade, sendo encerrados somente sob o aval do Conselho de Procuradores, ou convertidos nas peças processuais para tramitar no sistema judiciário.

O conteúdo desses editais, selecionado por temáticas de atuação do MPMS, originou um parâmetro para a análise da produção noticiosa disseminada pela Assecom no portal virtual do órgão. Para a coleta desses dois tipos de dados, editais e produção noticiosa do portal, foi usada a técnica esclarecida por Bauer e Aarts (2007, p.39) da amostragem representativa, delimitada por datas distintas de um mesmo período.

\section{Dados coletados e principais inferências}

Foi delimitado analisar três dias para cada mês do primeiro trimestre de 2011, resultando em trezentos e vinte e oito editais de apuração analisados entre os dias 10, 17 e 20 de janeiro, 3, 11 e 22 de fevereiro e 17, 24 e 30 de março de 2011. Tabulados um a um, obteve-se um gráfico que condensa em "áreas de atuação" todos os assuntos de que tratam esses editais. Esse agrupamento por área foi feito de acordo com definições do próprio MPMS, a exemplo de como a instituição organiza seus Centros de Apoio Operacional das Promotorias de Justiça em: 1) Consumidor, 2) Controle Externo da Atividade Policial, 3) Direitos Constitucionais do Cidadão e Direitos Humanos (Cidadania), 4) Eleitorais, 5) Fundações, 6) Habitação e Urbanismo e Patrimônio Histórico e Cultural, 7) Idoso e Pessoas Portadoras de Deficiência, 8) Infância e Juventude, 9) Meio Ambiente, 10) Patrimônio Púbico e Social.

Na configuração atual da instituição sobre esses Centros de Apoio, ainda existem duas coordenadorias separadas dessa definição, sendo as que auxiliam as promotorias de justiça cíveis e a outra, as promotorias criminais, em suas atuações junto ao sistema judiciário.

Figura 1 - Editais por área de atuação 


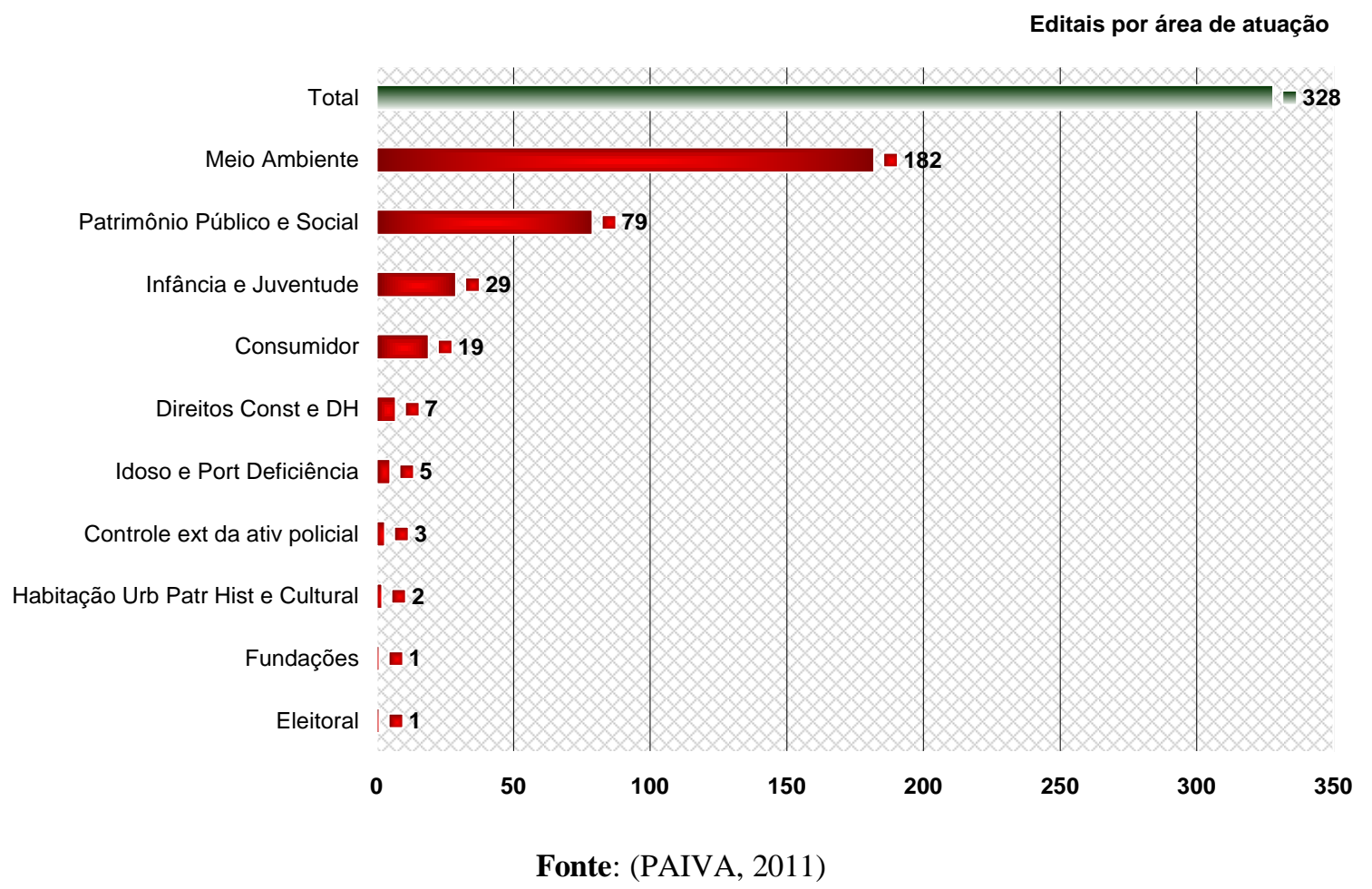

Dentre os trezentos e vinte e oito editais analisados, apareceram casos referentes a todas as áreas de atuação do MPMS, à exceção da área criminal, por esta demanda ser concernente a processos do judiciário, em publicação externa ao MPMS.

Para especificar as ocorrências reveladas, avaliou-se cada área descritivamente, com destaque para as áreas que mais vezes apareceram nos editais, entre Meio Ambiente, Patrimônio Público e Social, Infância e Juventude e Consumidor.

Destaca-se o universo de cento e oitenta e dois editais apurados sobre meio ambiente. A maior parte refere-se a apurações em cidades do interior do estado, com $61 \%$, o que representa mais de 50\% da amostra e revela a atuação do MPMS diante de uma das maiores características do Mato Grosso do Sul, um Estado de extensa área de preservação ecológica e ambiental. A existência de leis específicas para o meio ambiente determina a defesa ministerial diante das ocorrências de agressão e de irregularidades referentes a áreas de reserva legal e de proteção permanente.

Na sequência, estão os editais que tratam de Patrimônio Público, com setenta e nove casos; em seguida os de Infância e Juventude, com vinte e nove casos; Consumidor, dezenove; Direitos Constitucionais do Cidadão e Direitos Humanos, sete casos; Idoso e Portador de Deficiência, cinco 
casos; Controle Externo das Atividades Policiais, três casos; Habitação, Urbanismo e Patrimônio Histórico e Cultural, dois; e apenas um registro nas áreas Eleitoral e sobre Fundações.

\subsection{A produção noticiosa da assessoria de comunicação}

Como dito, a origem de temas que fazem parte da rotina de trabalho da instituição é fonte para o trabalho de produção de informação institucional nos moldes conceituais que apontamos serem teoricamente possíveis no jornalismo institucional no âmbito da comunicação pública.

Nesse sentido, a produção da assessoria de comunicação foi mapeada, pela amostragem representativa, permitindo saber até que ponto o fluxo de informação institucional tem escopo na produção jornalística do órgão. Especificamente, foi possível constatar qual a fonte produtora da informação de conteúdo jornalístico publicada no espaço dedicado exclusivamente à publicação de notícias no Portal do MPMS, ${ }^{4}$ frisando que a obtenção de material coletado seguiu o mesmo método de coleta dos editais, sendo tabulados três dias aleatórios para cada mês, entre janeiro e março de 2011.

É preciso lembrar que essa análise busca tão somente aferir se a produção noticiosa tem alguma equivalência ou referência às temáticas que mais apareceram nas investigações dos promotores de justiça expressas pelos editais. Isto porque a utilização do que foi publicado como edital nem sempre é possível, com apurações de pouca consistência ou, como foi aferido, os editais muitas vezes são publicados bem depois que os fatos ocorreram, em tempos nem sempre condizente com a urgência jornalística dos acontecimentos.

Figura 2 - Fontes de produção de matéria publicada no portal do MPMS

\footnotetext{
${ }^{4}$ O portal do MPMS, www.mp.ms.gov.br, reúne todas as informações relativas ao órgão, com suas publicações oficiais e extraoficiais. Inclui as leis que o regem, nomes e funções dos seus integrantes, atos e campanhas institucionais, entre outros dados.
} 


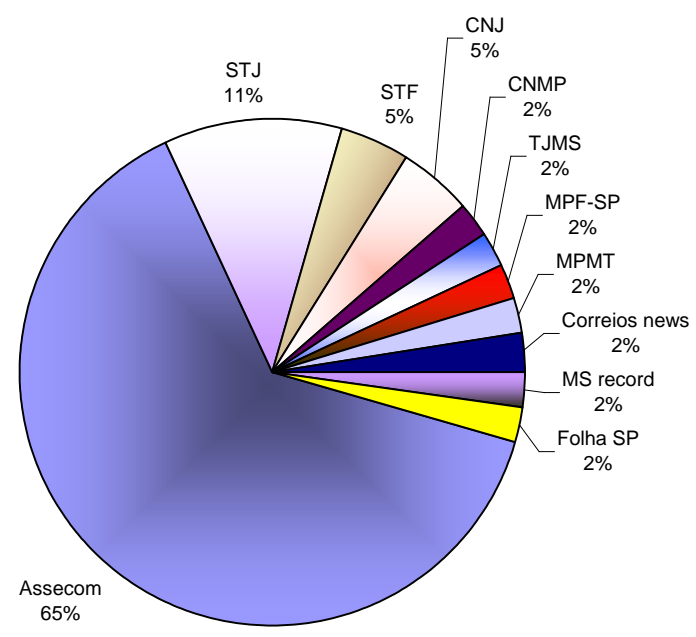

Fontes de produção

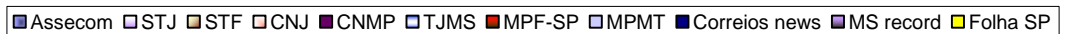

Fonte: (PAIVA, 2011)

Assim, de um total de nove dias, obtiveram-se quarenta e quatro matérias publicadas no portal. Vinte e oito delas são textos produzidos pela Assecom, ou seja, 65\% das publicações analisadas. Dezessete matérias são provenientes de outros portais (portanto, produções informativas externas), conforme o gráfico (figura 02) sobre as fontes de produção das matérias postadas no portal virtual do MPMS.

A utilização de outras fontes de produção divulgadas no portal do MPMS é usual, representando $35 \%$ do gráfico e buscam acompanhar o que é notícia de destaque no universo jurídico, principalmente decisões dos tribunais. $\mathrm{Na}$ análise, a fonte que mais aparece (11\%) é o Superior Tribunal de Justiça, STJ, com cinco matérias publicadas. Nenhuma destas faz referência direta a processos originários do MS. Em relação ao Supremo Tribunal Federal, STF, o período analisado traz duas matérias abordando decisões na área criminal, sendo uma referente a processo originário de MS sobre violência contra a mulher (Lei Maria da Penha) e a outra, de processo do Estado de São Paulo. Outra decisão referente a processo de MS é citada em matéria produzida pelo Tribunal de Justiça de Mato Grosso do Sul, TJMS, sobre atuação do MPMS em assunto de poluição sonora (meio ambiente), ocorrida em Campo Grande. 
Com relação às publicações de autoria interna ao órgão, os textos foram analisados de maneira a buscar a diversidade temática proposta pelas áreas de atuação do MPMS, conforme demonstra o que foi apresentado a partir dos editais. Logo se percebeu a desproporção de produção com a demanda de atuação da instituição, tendo muitas abordagens de interesse restrito, interno à instituição.

Para maior compreensão dos $65 \%$ do conteúdo publicado no portal do MPMS produzido pela Assecom (as 28 publicações) foi classificado o conteúdo com as mesmas categorias temáticas usadas no estudo dos editais, portanto, a partir das áreas de atuação do órgão. Para diferenciar as abordagens de interesse público, os textos de conteúdo restrito à instituição foram denominados como informação organizacional, conforme o resultado visualizado na próxima página, pela figura 3, sobre a produção de informações para o portal de notícias virtual do MPMS.

Especificamente, são vinte e oito matérias de autoria da Assecom, a maioria relacionada a interesses restritos à instituição ou à sua forma de atuação, surgindo o percentual de $85 \%$ do universo das 28 publicações. Dão destaque para as personalidades do órgão, com enfoque para a cúpula administrativa. Nas abordagens, situações e decisões que alteram e amparam administrativamente a atividade-fim de MP, ao passo que a atividade fim é abordada nos demais 15\% como demonstrado pelo gráfico seguinte (Criminal e Idoso e Portador de Defiência) sobre as produções encontradas no portal entre os dias 7, 17 e 28 de janeiro, 4, 18 e 25 de fevereiro e 3, 15 e 25 de março de 2011.

Nas narrativas, enunciados sobre a participação de procurador em solenidades, realização de evento e criação de medidas para contribuir na área de atuação criminal, processos seletivos para estagiários, homenagem a promotor, participação da instituição em programa de ajuda às vítimas das chuvas no Rio de Janeiro, eleições de sindicato de funcionários, formulários padronizados para inspeções carcerárias, reuniões e palestras diversas, mudanças na carreira e alteração de promotores em comarcas, estruturação com entrega de veículos a comarcas do interior, calendário de expediente e feriados, sorteio entre membros do MPMS para participarem de evento internacional, e ainda, três matérias com anúncio do conteúdo do programa de TV gerenciado pela Assecom, MPE na TV. Entre essas matérias constam abordagens acerca da instituição do MP e da atuação dos seus órgãos Ouvidoria-Geral e Corregedoria-Geral do MPMS. 
Figura 3 - Abordagem das matérias produzidas pela ASSECOM/MPMS

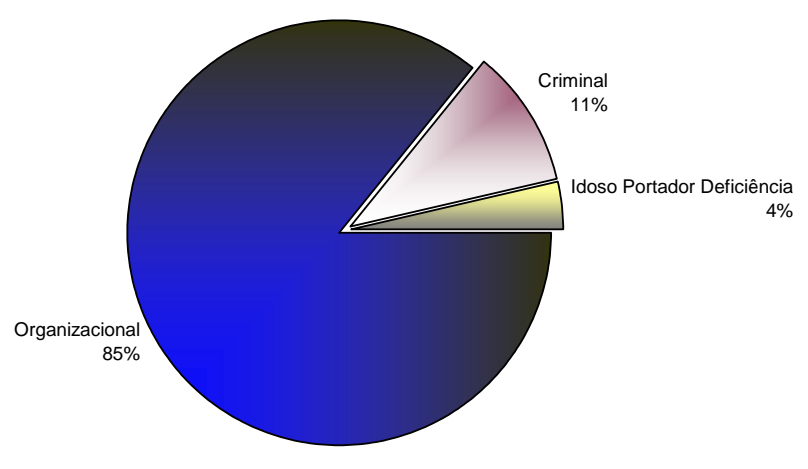

Abordagens textuais



Fonte: PAIVA (2011)

Precisamente, a figura 3 demonstra, além da categoria organizacional avaliada, duas fatias representativas das cinco matérias sobre os afazeres relativos às áreas de atuação do MPMS. Três delas tratam da área Criminal (11\%), sobre casos de apuração ocorridos em diferentes cidades, entre investigação de lesão corporal (Lei Maria Penha), cumprimento de mandados de busca e apreensão por crimes contra a administração pública e a terceira pode ser considerada com um anúncio, pois trata da programação de programa sobre a atuação de promotoria de justiça em crimes que acontecem em área de fronteira. A outra fatia (4\%) trata da atuação na área Idoso e Portador de Deficiência Física, sobre acordo feito para que se cumpra uma lei de repasse de verbas para manutenção de um asilo.

Conforme os depoimentos, as produções textuais da Assecom são feitas a partir do acompanhamento da agenda da chefia organizacional, principalmente a relacionada aos compromissos do Procurador-Geral de Justiça. Quanto aos demais órgãos, principalmente os relativos às comarcas do interior, há dependência do que comunicam os promotores e procuradores. 
Geralmente isso acontece por telefonemas ou encaminhamento de e-mail com envio de ações civis, acordos ou resumos dos seus afazeres, derivando em textos da Assecom publicados no portal. A linguagem jurídica desses encaminhamentos acaba prevalecendo e sendo repassada nas matérias produzidas, como se pode conferir no arquivo online de notícias do portal da instituição.

Observado com rigor, o conteúdo produzido pela Assecom pouco corresponde ao que indica Weber e Coelho (2011) sobre o se espera de notícias nos diferentes órgãos públicos: por serem produzidas por jornalistas que conhecem e dominam as rotinas, conceitos, procedimentos e políticas públicas desenvolvidas pela instituição, contribuam com a construção de conhecimento sobre questões e temas por ela tratados.

Sobre a rotina da Assecom, o acompanhamento dos editais ou uma frequência de contatos com os promotores e procuradores é feito sem muita regularidade, geralmente acontece somente quando há alguma provocação de jornalistas da mídia externa que acompanham as publicações e requerem mais informações. Nesse caso, a assessoria, na disputa por visibilidade ou controle de imagem com o sistema midiático, atua estrategicamente a partir dessa perspectiva e não necessariamente pela demanda colocada em ofertar informação pública. Falta o tratamento jornalístico capaz de atender ao interesse público e subsidiar o debate do público afetado ou interessado pelas ações constitucionais de Ministério Público.

Segundo o jornalista responsável, ouvido para o estudo de caso, a quantidade de fontes existentes no interior do próprio Ministério Público analisado faz com que as prioridades sejam dadas de acordo com a agenda da direção geral, nas determinações da Procuradoria-Geral, seguida pelo colegiado que a forma. Subsequente, é feito assessoramento aos demais, o que inclui apoiar promotores de justiça em suas atuações e no atendimento à imprensa, em produção de material publicitário, matérias para os veículos internos, relises à imprensa e ainda assessorando-os em eventos. A demanda por esses serviços, principalmente em relação aos promotores das comarcas do interior, é atendida conforme solicitações do próprio promotor para a procuradoria-geral ou diretamente à chefia da assessoria de comunicação. Identificou-se a necessidade de um acompanhamento programado ou de ações comunicacionais planejadas que pensem o MPMS de forma mais orgânica e integrada no conjunto de seus órgãos internos e áreas de atuação.

\section{Considerações finais}


A partir dos dados e análises realizadas, constata-se que a informação difundida pela assessoria de comunicação do Ministério Público de Mato Grosso do Sul prioriza questões e temas de interesses muito específicos e personalizados em prejuízo ao interesse público.

O tratamento dado a informações organizacionais pela assessoria contribui para a compreensão da instituição, porém, as temáticas relativas à finalidade da instituição deveriam ter abordagem, no mínimo, proporcional entre a abordagem de projeção organizacional e das temáticas de atuação, de forma a demonstrar equilíbrio e evidências integradas ao interesse público, voltadas à perspectiva da cidadania.

As interferências de promotores e procuradores na comunidade, suas ações e peças jurídicas, indicam situações a serem disponibilizadas como informação a ser gerenciada em suas fases de busca e coleta, tratamento, distribuição e avaliação das necessidades dessa informação, adequadas à exposição no espaço público pelos dispositivos de comunicação do órgão e, por consequência, para a mídia em geral.

Revela-se que a assessoria de comunicação e o jornalismo institucional, configurado sob a perspectiva pública da Comunicação necessita ter como parâmetro operacional a dimensão conceitual que o insere não como ferramenta, funcionalmente, no interior dos processos da instituição, mas como constituinte das práticas institucionais do sistema de justiça, pela própria natureza dessas instituições no contexto democrático.

Para tanto, é necessário desvelar uma questão central identificada no estudo e que, no entendimento das reflexões feitas, requer a problematização: como equacionar, com fundamentos e diretrizes claras, o que Weber e Coelho (2011, p.73) pontuam como competência da comunicação pública. Ou seja, a obtenção de visibilidade, capacidade de informar, promover atores, instituições e projetos e, especialmente, estabelecer relações e comunicação com a sociedade, que confere ao Estado poder para enfrentamentos simbólicos com informações que circulam na esfera da comunicação midiática, garantindo, no caso do jornalismo institucional público, possibilidades para produção da informação como direito e não como meio de gestão da imagem do órgão público para um fim alheio à própria razão de ser da instituição.

Sobre a assessoria de comunicação, especificamente, o desafio é rever práticas que ampliem o escopo das ações de comunicação para a instituição na busca por visibilidade, reafirmando princípios básicos para a produção de informação jornalística que incluam: tratamento plural, polifonia de vozes, apuração e checagem e a prática da reportagem. São elementos capazes de 
orientar o agendamento e a visibilidade da instituição diante dos públicos e dos sistemas midiáticos pelo vigor do discurso jornalístico (linguagem que aflora conflitos) em sua histórica função perante uma esfera pública vigorosa e plural de debates, em detrimento da visibilidadade institucional como fim em si mesmo.

\section{Referências}

AVRITZER, Leonardo. Modelos de deliberação democrática: uma análise do orçamento participativo no Brasil. In SANTOS, Boaventura de Sousa (Org.). Democratizar a democracia: os caminhos da democracia participativa. Rio de Janeiro: Civilização Brasileira, 2002. p. 561-598. BONETI, Lindomar Wessler. Políticas públicas por dentro. Ijuí: Ed. Unijuí, 2006. BAUER, Martin W.; AARTS, Bas. A construção do corpus: Um princípio para a coleta de dados qualitativos. In: BAUER, Martin W.; GASKELL, George (Orgs.). Pesquisa qualitativa com texto, imagem e som: um manual prático. Petrópolis/RJ: Editora Vozes, 2007.

BRANDÃO, Elizabeth Pazito. Conceito de comunicação pública. In: DUARTE, Jorge (Org.).

Comunicação pública: estado, governo, mercado, sociedade e interesse público. São Paulo: Atlas, 2009. p.1-33.

BRASIL. Constituição da República Federativa do Brasil: promulgada em 5 de outubro de 1988. Disponível em: <http://www.planalto.gov.br/ccivil_03/constituicao/constitui\%C3\%A7ao.htm>. Acesso em: 04 abr. 2011.

DUARTE, Jorge. Assessoria de imprensa e relacionamento com a mídia: teoria e técnica. São Paulo: Atlas, 2002.

. Instrumentos de comunicação pública. In: DUARTE, Jorge (Org.). Comunicação pública: estado, governo, mercado, sociedade e interesse público. São Paulo: Atlas, 2009. p. 59-71.

DUARTE, M. Y. M. Estudo de caso. In: DUARTE, Jorge; BARROS, Antonio (Orgs.).

Métodos e técnicas de pesquisa em comunicação. São Paulo: Atlas, 2006. p. 215-235.

FAUSTO NETO, Antônio. Mudanças da Meduza? A enunciação midiatizada e sua incompletude. In: FAUSTO NETO, Antonio et al. (Orgs). Midiatização e processos sociais na América Latina. São Paulo: Paulus, 2008a . p.119-144.

GIL, Antonio Carlos. Como elaborar projetos de pesquisa. 3. ed. São Paulo: Atlas, 1991.

KARAM, Francisco José Castilhos. Jornalismo, ética e liberdade. São Paulo: Summus, 1997. LASSANCE, Antonio. Comunicação institucional do poder público. In: CASTRO, Daniel; MELO, José Marques de; CASTRO, Cosette (Orgs.). Panorama das telecomunicações no Brasil. Brasília: Ipea, 2010. p. 167-182.

MATOS, Heloiza. Comunicação Pública, Esfera Pública e Capital Social. In: DUARTE, Jorge (Org.). Comunicação pública: Estado, Mercado, Sociedade e Interesse Público. $2^{a}$ ed. São Paulo: Atlas, 2009a. p. 47-58.

. Capital social e comunicação: interfaces e articulações. São Paulo: Summus, 2009b.

MATTELART, A. História da sociedade da informação. São Paulo: Loyola, 2006.

MONTEIRO, Graça França. A singularidade da comunicação pública. In: DUARTE, Jorge (org). Comunicação Pública: estado, mercado, sociedade e interesse público. São Paulo: Atlas, 2009. p. 34-46. 
PAIVA, C. S.de. A comunicação da informação de interesse público no Ministério Público do estado de Mato Grosso do Sul. 2011. 144 f. Il. Dissertação (Mestrado em Comunicação) Universidade Estadual Paulista Julio de Mesquita Filho, Bauru, 2011.

PITTA, Aurea Maria da Rocha. Comunicação, promoção da saúde e democracia: políticas e estratégias de comunicação no Sistema Único de Saúde no Brasil. 2001. Tese (doutorado). Programa de Pós-Graduação em Comunicação - Universidade Federal do Rio de Janeiro, 2001. RAMOS, M.C. Comunicação, direitos sociais e políticas públicas. In: MARQUES DE MELO, J.; SATHLER, L (orgs). Direitos à comunicação na sociedade da informação. São Bernardo do Campo, SP: Umesp, 2005. p. 245-253.

RAMOS, M.C; SANTOS, Suzy dos (Orgs.). Políticas de comunicação: buscas teóricas e práticas. São Paulo: Paulus, 2007.

SANTOS, Boaventura de Sousa; AVRITZER, Leonardo. Para ampliar o cânone democrático In: SANTOS, Boaventura de Sousa (org). Democratizar a democracia: os caminhos da democracia participativa. Rio de Janeiro: Civilização Brasileira, 2002.p.39-84.

SARDINHA, A.C. A Comunicação da Informação de Interesse Público no Ministério Público do Estado de Mato Grosso do Sul. 2011. 239 f. (Dissertação de Mestrado) - Universidade Estadual Paulista Julio de Mesquita Filho, Bauru, 2011.

SIGNATES, L. Comunicação como política pública: da abrangência teórica às questões políticas. Ser, Goiânia, v.1, n.1, p.4-19, jul./dez. 2009

SIGNATES, Luiz. Epistemologia da comunicação na democracia: a centralidade do conceito de comunicação na análise dos processos políticos. In: Encontro anual da Associação Nacional dos Programas de Pós-Graduação, 10, 2011, Porto Alegre. Anais... Porto Alegre: Compós, 2011. Disponível em: <http://www.compos.org.br/data/biblioteca_1659.doc>. Acesso em: 02 jun. 2012.

SOUSA, J. P. Teorias da notícia e do jornalismo. Chapecó: Argos, 2002.

SOUZA, R. L.S de. A “cordialidade” na gramática política brasileira e seus efeitos na (in) definição de políticas universais e democráticas de comunicação. In: RAMOS, M.C; SANTOS, Suzy dos (orgs). Políticas de comunicação: buscar teóricas e práticas. São Paulo: Paulus, 2007, p. 149-174. VIZER, E.A. La trama (in) visible de la vida social: comunicación, sentido y realidad. Buenos Aires: La Crujía, 2006.

WEBER, M.H; COELHO, M.P. Entre jornalismos e poderes. IN SILVA, Gislene; KÜNSCH, Dimas A.; BERGER, Christa \& ALBUQUERQUE, Afonso (Orgs.). Jornalismo contemporâneo: figurações, impasses e perspectivas. Salvador, Edufba/COMPÓS, 2011. p. 51-78.

WOLF, Mauro. Teorias da Comunicação. Lisboa: Editorial Presença, 1995.

WOLTON, Dominique. É preciso salvar a comunicação. São Paulo: Paulus, 2006.

YIN, Robert K. Estudo de caso: planejamento e métodos. 3. ed. Porto Alegre: Bookman, 2005. 